\title{
Preliminary Assessment of Acute and 28-Day Repeated Dose Oral Toxicity of a Newly Developed Herbal Mixture on Experimental Animal
}

\author{
Soumendra Darbar ${ }^{1,2}$, Srimoyee Saha ${ }^{3}$, Kausikisankar Pramanik², Atiskumar Chattopadhyay,"* \\ ${ }^{1}$ Faculty of Science, Jadavpur University, Raja SC Mallick Road, Kolkata, West Bengal, INDIA \\ ${ }^{2}$ Department of Chemistry, Jadavpur University, Raja SC Mallick Road, Kolkata, West Bengal, INDIA \\ ${ }^{3}$ Department of Physics, Jadavpur University, Raja SC Mallick Road, Kolkata, West Bengal, INDIA
}

\begin{abstract}
Objectives: Toxicity is an expression of being poisonous, indicating the state of adverse effects led by the interaction between toxicants and cells. The present study was designed to evaluate the acute oral toxicity study and 28 days repeated toxicity study of Herbal Mixture (HM) according to OECD guidelines. Materials and Methods: In acute oral toxicity study, Herbal mixture was administered at $2000 \mathrm{mg} / \mathrm{kg}$ orally and animals were observed for toxic signs at $30 \mathrm{~min}, 1,2$ and $4 \mathrm{hr}$ and thereafter once a day for the next 14 days. In repeated dose-28-day toxicity study, the animals were divided into four groups of 6 animals each. Group- 1 animals served as a control. Group II Animals received low dose of test drug $100 \mathrm{mg} / \mathrm{kg}$ (orally). Group III animals received middle dose of test drug $200 \mathrm{mg} / \mathrm{kg}$ (orally) once daily for 28 days respectively. Group IV animals received high dose of test drug $400 \mathrm{mg} / \mathrm{kg}$ (orally) once daily for 28 days respectively. Results: The study results showed that neither the acute toxicity study of herbal mixture at the dose level of $2000 \mathrm{mg} / \mathrm{kg}$ nor the repeated dose study did not produce any toxic sign or mortality during study. In repeated dose toxicity study, no significant changes were observed in the haematological and biochemical parameters, relative organ weight, gross necropsy and histopathological examination with herbal mixture treatment. Conclusion: The results of the present study suggest that $L_{50}$ of newly developed Herbal Mixture $(\mathrm{HM})>2000 \mathrm{mg} / \mathrm{kg}$ and the mixture is completely safe and non-toxic for therapy.
\end{abstract}

Key words: Acute oral toxicity, Sub acute toxicity, Herbal mixture, Haematology, Liver function test, Histology.

\section{INTRODUCTION}

Medicinal plants have burgeoned in recent times due to increased efficiency of drugs derived from plants, growing interest in natural products and raising concerns about the side effects of conventional medicine. ${ }^{1}$ Herbal drug combinations have shown that they possess better efficacy and reduced side-effects in comparison with single herbal drugs. The World Health Organization (WHO) estimates that $80 \%$ of the world's population relies on these "alternative" plant-based medicines as their primary medical intervention especially in the developing and in the developed countries where modern medicines are predominantly used. ${ }^{2}$ Over the years, the use of herbs in the treatment of illnesses has been very successful and its historic usage has been useful in drug discovery development. Herbal prescriptions and natural remedies are commonly employed in developing countries for the treatment of various diseases. ${ }^{3,4}$

Toxicology may be defined as the study of harmful/poisonous effects of drugs and other chemicals with emphasis on detection, prevention and treatment of poisonings. After gaining relevant information on the harmful effects of a compound, the levels for its safe usage or the degree of its safety is established, this is known as its
Submission Date: 30-04-2019; Revision Date: 12-06-2019; Accepted Date: 27-10-2019

DOI: 10.5530/ijper.54.1.16 Correspondence: Dr. Atiskumar Chattopadhyay, Faculty Council of Science, Jadavpur University, Raja SC Mallick Road, Kolkata-700032, West Bengal, INDIA. Phone: +919433144548 E-mail: atischatterjee@gmail. com

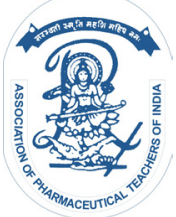

www.ijper.org 
(compound) Biosafety level. ${ }^{5}$ Acute toxicity testing in animals is typically the initial step in the assessment and evaluation of the health effect characteristics of a test substance and its primary purpose is to provide information on potential health hazards that may result from a short term exposure.

Traditional and alternative medicine is extensively practiced in the prevention, diagnosis and treatment of various illnesses. It has attracted increasing public attention over the past 20 years as this type of medicine is easily accessible in some regions. ${ }^{6}$ Medicinal plants contribute great importance in daily life by providing wide range of nutrients, vitamins and other compounds which widen in therapeutic arsenal. In general, natural products play a dominant role in the development of novel drug leads for the treatment and prevention of diseases. ${ }^{7}$ Medicinal plants behave as authentic medicines because the chemical substances of which they are formed can have a biological activity in humans. Determination of efficacy and safety of herbal remedies is necessary because many people using these agents as self-medication. Since, there is limited data available about the safety of the commonly used herbal remedies, therefore, efforts to elucidate health benefits and risks of herbal medicines should be intensified. ${ }^{1}$ It is the need of the hour to evaluate acute and chronic toxicities of herbal drugs. ${ }^{8}$ Herbal formulations available with a wide range of indications like protective to liver, appetite and growth promoters, gastrointestinal and hepatic regulator, as treatment for hepatic dysfunction, for hepatic regeneration as well as liver stimulant and tonic. Despite the widespread use, there is a lack of scientific evidence on their efficacy and safety. In fact, there is lack of evidence on quality, safety and efficacy of many herbal preparations. Although many herbal preparations are non-toxic, many plants currently used for medicines have been shown to be highly toxic when given either acutely or sub-chronically. ${ }^{9,10}$ The increasing number of plant based medication users around the globe and lack of experimental reports on their safety make it basic to direct toxicological investigation on natural herbal products. ${ }^{11,12}$

Herbal medicines have attained the widespread acceptability as natural therapeutic agents for various diseases like diabetes, arthritis, renal and liver diseases, obesity and cardiovascular disorders. It is proved that herbal combination made up of different herbs which produce maximum therapeutic outcomes than the individual herbs. These combinations are employed for the betterment of various chronic disorders. Currently worldwide there is need to found out the safe, less toxic, cost effective polyherbal remedies that can be effective against various chronic diseases like diabetes, obesity, liver dysfunction. Here we developed a herbal formulation which is made up of six Indian medicinal plants and three medicinal species with minimum quantity and maximum therapeutic potential. We hope the newly developed herbal medicine may be very effective to treat the various chronic diseases. Hence it has become necessary to standardize the preclinical safety and efficacy study on animal model for further therapeutic study to establish the formulation as a drug. So, in the present study, toxic effects of Herbal Mixture (HM) in swiss albino mice were conducted at dose of $2000 \mathrm{mg} / \mathrm{kg}$ body weight for a period of 14 days for the acute toxicity study (followed OECD 402 guideline); and at dosages of 100, 200 and $400 \mathrm{mg} /$ $\mathrm{kg}$ body weight for a period of 28 days for the sub-acute toxicity study (followed OECD 410 guideline).

\section{MATERIALS AND METHODS}

\section{Experimental animals}

Swiss albino wistar mice (30-40g) were obtained from the animal house of Jadavpur University. The room was well ventilated and maintained on light for $12 \mathrm{hr}$ and 12 $\mathrm{hr}$ darkness. Temperatures were maintained at $27-30^{\circ} \mathrm{C}$. The mice were provided with the standard pellets and clean water ad libitum. The experimental procedures were carried out in strict compliance with the Institutional Animal Ethics Committee's (IAEC) rules and regulation of this institute and the experiments were carried out as per the guidelines of Committee for the Purpose of Control and Supervision of Experiments on Animals (CPCSEA) having IAEC No. IAEC/JU/s/8/2018.

\section{Composition of herbal formulation}

The composition of each $5 \mathrm{ml}$ of Herbal mixture compose of Azadirachtaindica (Neem)50mg; Curcuma longa (Turmeric) 20mg; Terminalia chebula (Chebulic myrobalan) 20mg; Aloe barbadensis Miller (Aloe Vera) 20mg; Tinospora cordifolia (guduchi) 20mg; Citrus limon (Lemon)10mg; Trigonella foenum graecum (Methi) 10mg; Piper nigrum (Black pepper) 10mg; Elettaria cardamomum (cardamom) 10mg (Figure 1).

\section{Assessment of Acute toxicity test}

Acute toxicity study was performed in healthy swiss albino mice (30-40gm) as per guidelines (AOT 425) suggested by the Organization for Economical Co-operation and Development (OECD). The animals were randomly assigned into two groups of 5 mice each and kept overnight fasting prior to extract administration. Group 1 served as the control and the mice were orally administered with $2 \mathrm{ml}$ distilled water. Single concentrations of the polyherbal extract $2000 \mathrm{mg} / \mathrm{kg}$ body weight 


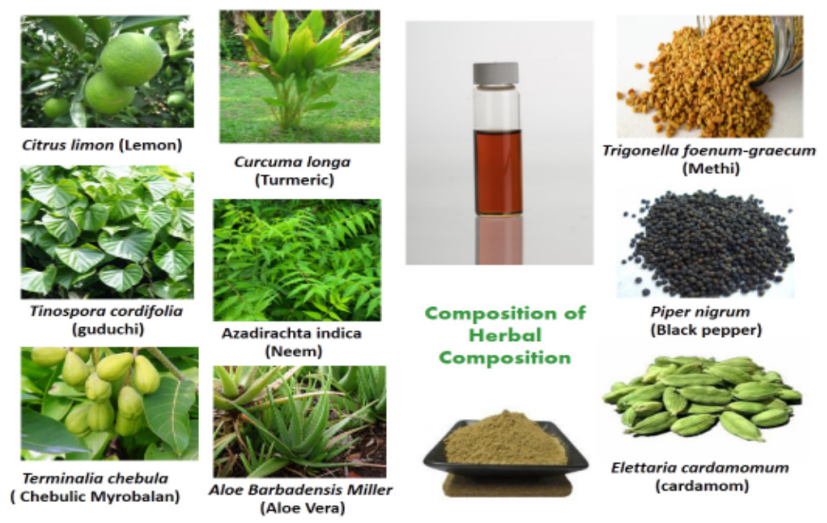

Figure 1: Composition of Herbal Mixture.

was constituted in $5 \mathrm{ml}$ distilled water through a mice gavage. Food was withheld for further $3 \mathrm{hr}$.

The mice were observed after every 30 min post extract administration for the first $2 \mathrm{hr}$ and later once a day up to the $14^{\text {th }}$ for changes in skin and fur, eyes and mucus membranes, behavior pattern, tremors, salivation, diarrhea, sleep, coma, mortality, moribund, ill health or any visible reaction to treatment. Weight recording was done before extract administration, at day 1, day 7 and day 14 using a sensitive balance.

\section{Clinical Observation}

The treated animals were observed for mortality (twice daily) and the clinical signs were recorded to note the onset, duration and reversal (if any) of toxic effect at 2, 4, 6 and $8 \mathrm{hr}$ after the administration of last substances and once daily thereafter for 14 days. The routine cage side observation s included changes in skin and fur, eye and mucus membrane, somatomotor activity, general behavior pattern were noted. Clinical symptoms like arching of the back, alopecia, wound, nasal discharge, lacrimation and loose stool were also recorded during the observation.

\section{Body weight}

Body weight data of individual animals were recorded following the period of fasting on the day of dosing, weekly thereafter and at termination on day 15 . Weekly changes in body weight gain were calculated and recorded.

\section{Repeated dose 28-day oral toxicity study}

Sub-acute (Repeated dose 28-day oral toxicity study) was carried out as per OECD guidelines Guideline-407 2. Healthy Swiss albino mice were used for the study. The Animals were divided into four groups of 6 animals each. Group-1 animals served as a control animals. Group II Animals received low dose of test drug (Herbal formulation) $100 \mathrm{mg} / \mathrm{kg}$ orally. Group III animals received middle dose of test drug $200 \mathrm{mg} / \mathrm{kg}$ orally. Group IV animals received high dose of test drug $400 \mathrm{mg} / \mathrm{kg}$ orally. The animals were administrated with the study drug once daily for 28 days. The doses were selected as par various previous studies. All the experimental animals were observed for clinical signs of mortality and morbidity once a day, at the same time each day, till the completion of treatment.

\section{Haematological study}

On the last day of dose administration all the animals were kept for overnight fasting (water ad libitum). The overnight fasted animals were anaesthetized under general anaesthesia using isoflourane, blood samples were collected using heparinised microhematocrit tubes by retro-orbital puncture into a potassium EDTA containing blood collection tubes (for haematological) and 11\% w/v Tri-sodium Citrate (TSC) containing tubes (for biochemical fanalysis). Blood smear was prepared from the EDTA containing blood sample, air dried and stained (Hemacolor rapid staining of blood smear, E.Merck, Mumbai, India) for Differential Leukocyte Count (DLC). Haematological analysis were performed using automated haematology analyser (Model PE 6000 Rapid Diagnostics Pvt Ltd, New Delhi, India), which includes analysis of haemoglobin (HGB), Red Blood Cell count (RBC), White Blood Cell count (WBC), platelet count and Hematocrit (HCT).

\section{Liver function test}

The plasma thus collected was analysed for glucose, triglyceride, cholesterol, Alkaline Phosphatase (ALP) Aspartate Transaminase (AST) Alanine Transaminase (ALT) Lactate Dehydrogenase (LDH), total bilirubin creatinine, urea, protein and albumin levels by using biochemical kits (Accurex Biomedical Pvt. Ltd, Thane, India) in semi-automated biochemical analyser (Model: Star 21 Plus, Rapid Diagnostics Pvt Ltd, New Delhi, India).

\section{Statistical analysis}

Data were expressed as mean \pm standard error mean. Data obtained from repeated dose studies were analysed by Student's $t$-test using GraphPad prism 5.0 to determine significant difference between the means of control and test groups. $p$ value 0.05 was considered significant.

\section{RESULTS AND DISCUSSION}

Traditional medicine has maintained greater popularity all over developing world and the use is rapidly on the increase. Despite this, the safety of herbal medicine 
use has recently been questioned due to reports of illness and fatalities; hepatotoxicity and nephrotoxicity. Although there are many traditional herbal medicines available, only a few have been verified by clinical trials, their efficacy and safety are still questioned by consumers. $^{13,14}$

Observation included the change in skin, fur, eyes and mucus membrane. Appearance of toxicity related to central nervous system, Cardiovascular system and Autonomic nervous system such as tremors, convulsions, sedation, stereotypic behaviour, respiratory distress, cardiovascular collapse, response to sensory stimuli, salivation, diarrhea, pilo erection, Muscular coordination, Muscular grip, posture, gait, limb paralysis, lethargy, sleep, coma and mortality were observed with special attention (Table 1). The results revealed no treatment related death or signs of toxicity in the treated animals in all the doses throughout the study. Body weight gain of both male and female mice was also observed (Table 2) when compared with before and after treatment of the observed groups (Figure 2). Further, there were no gross pathological abnormalities which prove the $\mathrm{LD}_{50}$ value was found to be greater than $2000 \mathrm{mg} /$ kg b.wt.

There were no treatment-related toxicity signs and mortality observed in mice treated at $100 \mathrm{mg}, 200 \mathrm{mg}$ and 400 $\mathrm{mg} / \mathrm{kg}$ orally for a period of 28 days and in the satellite group of mice. Bodyweight gain was observed between control and treated groups during the study (Table 1). Food and water consumption of treated groups were found to be insignificant when compared to the control groups (Figure 3 and 4). Since there is no significance decrease in mean body weight and there is considerable increase in mean body weight of control and treatment groups.

Hematological profile such as Packed Cell Volume (PCV), Red Blood Cells (RBC) count, White Blood Cell Count (WBC), Platelet Count, Hemoglobin (Hb), Mean Cell Haemoglobin Concentration (MCHC), Mean Red Cell Volume (MCV), Mean Cell Hemoglobin $(\mathrm{MCH})$, Mean Platelet Volume (MPV), Neutrophils, Eosinophil's, Basophils, Lymphocytes and Monocytes were found to be within the normal physiological limits for rodents and no significant change has been observed in treatment groups when compared with the control groups (Table 3). Hence there are no serious toxicological implications such as destruction of Erythrocytes.

Lipid profiles such as HDL, LDL, VLDL, TGL and Total Cholesterol did not show any significant changes. The main product of protein metabolism is urea and an increased level of urea in the blood is an indicator of renal impairment (Table 4). The present study showed

\begin{tabular}{|c|c|c|c|c|c|c|}
\hline \multicolumn{6}{|c|}{ Table 1: Clinical observations of mice at $\mathbf{2 , 0 0 0 ~} \mathbf{~ m g} / \mathbf{k g}$ dose of Herbal Formulation (HF). } \\
\hline \multirow{2}{*}{ Signs and symptoms } & Male & Female & Male & Female & Male & Female \\
\cline { 2 - 7 } & Day $\mathbf{1}$ & Day $\mathbf{1}$ & Day $\mathbf{7}$ & Day $\mathbf{7}$ & Day $\mathbf{1 4}$ & Day $\mathbf{1 4}$ \\
\hline Behavior & Normal & Normal & Normal & Normal & Normal & Normal \\
\hline Somatomotor activity & Normal & Normal & Normal & Normal & Normal & Normal \\
\hline Skin and Fur & Normal & Normal & Normal & Normal & Normal & Normal \\
\hline $\begin{array}{c}\text { Eyes And mucous } \\
\text { membranes }\end{array}$ & Normal & Normal & Normal & Normal & Normal & Normal \\
\hline Salivation & Absent & Absent & Absent & Absent & Absent & Absent \\
\hline Diarrhoea & Absent & Absent & Absent & Absent & Absent & Absent \\
\hline Tremors/ convulsions & Absent & Absent & Absent & Absent & Absent & Absent \\
\hline Death & Nil & Nil & Nil & Nil & Nil & Nil \\
\hline Other symptoms & Nil & Nil & Nil & Nil & Nil & Nil \\
\hline
\end{tabular}

Values are mean \pm S.D $(n=6)$.

Table 2: Effect of Herbal Mixture (HM) on the body weight, Food consumption and Necropsy of mice at $2,000 \mathrm{mg} / \mathrm{kg}$ dose.

\begin{tabular}{|c|c|c|c|c|c|c|c|}
\hline \multirow{2}{*}{ Animals } & \multicolumn{3}{|c|}{ Body weight (g) } & \multicolumn{3}{c|}{ Food consumption (g) } & $\begin{array}{c}\text { Observed } \\
\text { lesions } \\
\text { during study }\end{array}$ \\
\cline { 2 - 8 } & Day 1 & Day 7 & Day 14 & Day 1 & Day 7 & Day 14 & Day 14 \\
\hline Male & $25.2 \pm 1.02$ & $27.6 \pm 1.03$ & $31.7 \pm 0.98$ & $4.62 \pm 0.06$ & $4.78 \pm 0.06$ & $5.01 \pm 0.05$ & $\mathrm{Nil}$ \\
\hline Female & $25.4 \pm 1.11$ & $27.9 \pm 0.94$ & $31.4 \pm 1.12$ & $4.81 \pm 0.05$ & $4.88 \pm 0.08$ & $5.15 \pm 0.04$ & $\mathrm{Nil}$ \\
\hline
\end{tabular}

Values are mean \pm S.D $(n=6)$. 
no significant changes pertaining to renal parameters. Serum marker enzymes are biochemical parameters associated with health indices and are of diagnostic significance in routine clinical evaluation of the state of health. Alanine amino Transaminase (ALT) and Aspartate amino transaminase (AST) are largely used in the assessment of liver damage by drugs or any other hepatotoxin (Table 4). So, to elucidate the toxicity produced during liver metabolism of drug, transaminase markers play a vital role. Aspartate Transaminase (AST), Alanine amino Transaminase (ALT) which are the indicators of hepatocellular injury also did not show any significant alterations in the polyherbal formulation treated groups and control groups. Serum MDA level did not show any significant alterations in the HM treated group and control group (Table 5). The histopathological studies revealed no significant weight changes and normal architectural changes in the vital organs such as heart, brain, lungs, spleen, kidneys, liver, stomach, testes and ovary suggesting that the preparationis devoid of serious organ degenerative potential both dose levels but high dose should have slight detrimental kidney, liver effect (Figure 5).

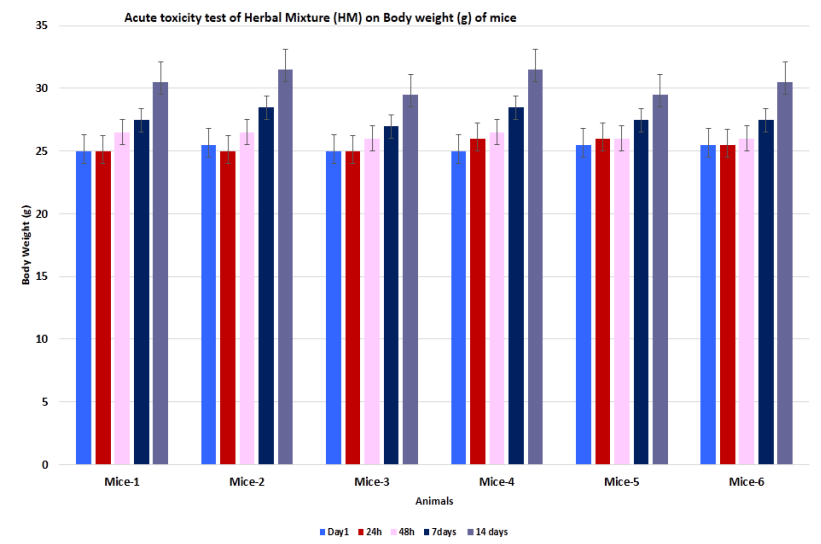

Figure 2: Acute Toxicity Test of HM on Body Weight.

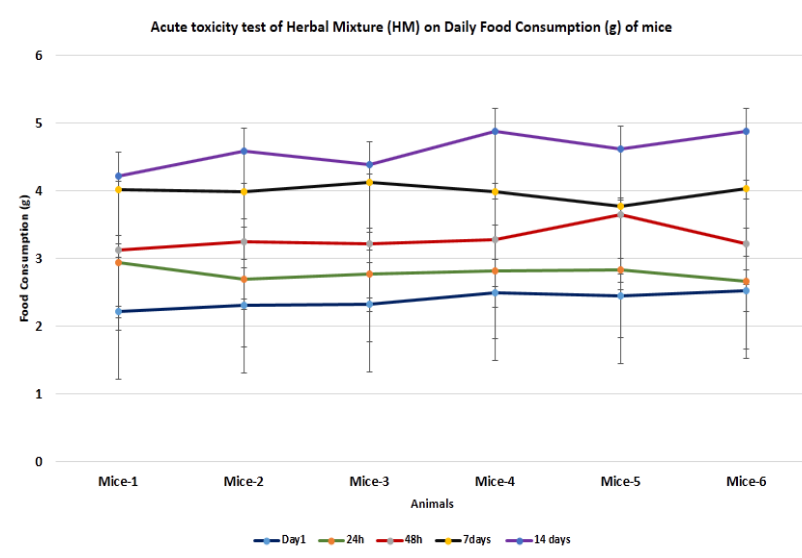

Figure 3: Acute Toxicity Test of HM on Daily Food intake.
World Health Organization estimated that $80 \%$ of the word's inhabitants still rely mainly on traditional medicines for their health care. The subcontinent of India is well-known to be one of the major biodiversity centers with about 45,000 plant species. In India, about 15,000 medicinal plants have been recorded, in which the communities used 7,000-7,500 plants for curing different diseases. In Ayurveda, single or multiple herbs (polyherbal) are used for the treatment. The 'Ayurvedic Literature Sarangdhar Sambita' highlighted the concept of polyherbalism to achieve greater therapeutic efficacy. The active phytochemical constituents of individual plants are insufficient to achieve the desirable therapeutic effects. When combining the multiple herbs in a particular ratio, it will give a better therapeutic effect and reduce the toxicity. Here we developed a herbal formulation which is made up of six Indian medicinal plants and three medicinal species with minimum quantity and maximum therapeutic potential. We hope the newly developed herbal medicine may be very effective to treat the various chronic diseases. The developed formulation is very affordable for the common mass for treatment in the common chronic disorders.

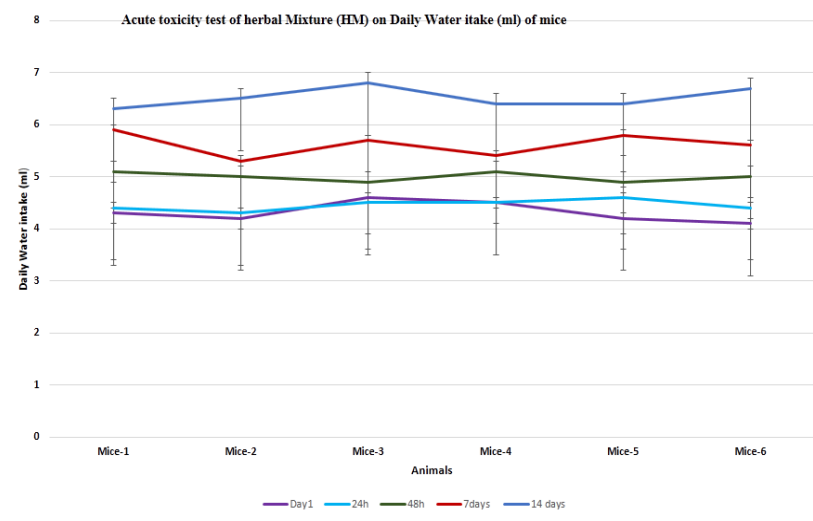

Figure 4: Acute Toxicity Test of HM on Daily Water Consumption.

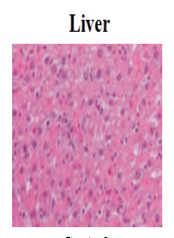

Control

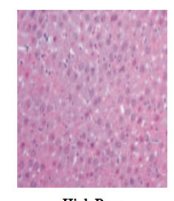

High Dose

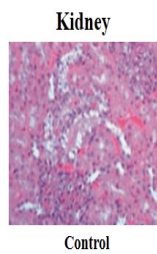

Control

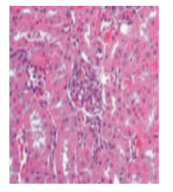

High Dose

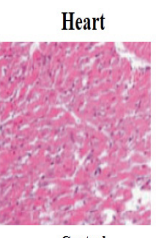

Control

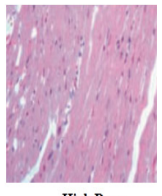

High Dose
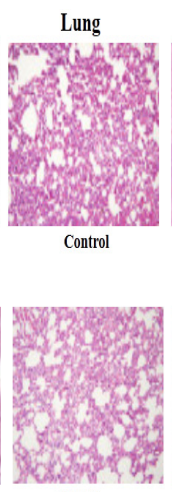

High Dose
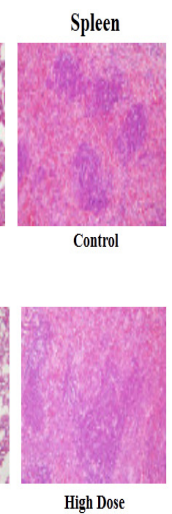

Figure 5: Histological examination of Herbal Mixture in different organs. 


\begin{tabular}{|c|c|c|c|c|c|c|c|c|}
\hline \multirow[t]{2}{*}{ Parameters } & \multicolumn{2}{|c|}{ Control } & \multicolumn{2}{|c|}{ HM $100 \mathrm{mg} / \mathrm{kg}$} & \multicolumn{2}{|c|}{$\mathrm{HM} 200 \mathrm{mg} / \mathrm{kg}$} & \multicolumn{2}{|c|}{$\mathrm{HM} 400 \mathrm{mg} / \mathrm{kg}$} \\
\hline & Male & Female & Male & Female & Male & Female & Male & Female \\
\hline $\mathrm{Hb}(\mathrm{g} \%)$ & $11.6 \pm 2.3$ & $11.2 \pm 2.1$ & $12.6 \pm 2.0$ & $12.2 \pm 1.9$ & $10.8 \pm 1.1$ & $10.4 \pm 1.5$ & $12.7 \pm 3.0$ & $12.5 \pm 3.1$ \\
\hline $\operatorname{RBC}\left(\times 10^{6} \mathrm{~cm}^{2}\right)$ & $10.8 \pm 2.3$ & $10.2 \pm 1.9$ & $11.5 \pm 1.0$ & $11.6 \pm 1.1$ & $9.1 \pm 1.1$ & $9.0 \pm 1.2$ & $10.4 \pm 3.2$ & $10.3 \pm 2.6$ \\
\hline RT (\%) & $2.8 \pm 0.5$ & $2.5 \pm 0.3$ & $4.8 \pm 0.6$ & $4.5 \pm 0.6$ & $3.1 \pm 0.9$ & $2.9 \pm 0.9$ & $2.5 \pm 2.4$ & $2.6 \pm 1.9$ \\
\hline НСТ (\%) & $34.1 \pm 6.2$ & $32.1 \pm 5.1$ & $36.4 \pm 5.4$ & $36.9 \pm 5.9$ & $30.7 \pm 3.2$ & $30.1 \pm 3.7$ & $38.6 \pm 2.6$ & $37.9 \pm 2.1$ \\
\hline $\operatorname{MCV}\left(\mu m^{3}\right)$ & $37.2 \pm 1.5$ & $37.1 \pm 1.5$ & $31.7 \pm 2.6$ & $31.0 \pm 2.5$ & $33.7 \pm 3.7$ & $33.2 \pm 3.2$ & $37.1 \pm 2.9$ & $37.1 \pm 1.8$ \\
\hline $\mathrm{MCH}(\mathrm{pg})$ & $21.4 \pm 2.6$ & $21.4 \pm 2.4$ & $21.9 \pm 3.3$ & $21.8 \pm 3.1$ & $21.5 \pm 5.4$ & $21.6 \pm 4.9$ & $22.6 \pm 2.6$ & $22.5 \pm 1.2$ \\
\hline MCHC (\%) & $40.2 \pm 6.5$ & $40.5 \pm 6.2$ & $36.5 \pm 6.2$ & $36.1 \pm 4.2$ & $38.2 \pm 5.9$ & $38.2 \pm 4.1$ & $32.4 \pm 5.2$ & $32.5 \pm 2.5$ \\
\hline Platelets & $6.5 \pm 1.2$ & $6.2 \pm 1.9$ & $5.5 \pm 1.1$ & $5.2 \pm 1.2$ & $3.9 \pm 1.0$ & $3.6 \pm 1.5$ & $4.8 \pm 1.1$ & $4.2 \pm 1.2$ \\
\hline $\begin{array}{c}\text { WBC }\left(\times 10^{5}\right. \\
\left.\mathrm{cm}^{2)}\right)\end{array}$ & $9.1 \pm 2.2$ & $9.4 \pm 2.1$ & $9.9 \pm 3.0$ & $9.1 \pm 2.6$ & $9.5 \pm 0.9$ & $9.7 \pm 0.8$ & $11.5 \pm 1.6$ & $11.1 \pm 1.3$ \\
\hline $\mathbf{L}$ & $72 \pm 5.1$ & $74 \pm 5.2$ & $79 \pm 6.5$ & $78 \pm 5.6$ & $74 \pm 4.9$ & $76 \pm 4.1$ & $74 \pm 5.5$ & $73 \pm 4.5$ \\
\hline $\mathbf{N}$ & $25 \pm 2.5$ & $24 \pm 2.3$ & $18 \pm 2.6$ & $19 \pm 2.1$ & $23 \pm 3.4$ & $24 \pm 3.1$ & $23 \pm 2.1$ & $25 \pm 1.2$ \\
\hline
\end{tabular}

Data are expressed as mean \pm standard deviation $(n=6)$

Hb: Haemoglobin; RBC: Read Blood corpuscle; RT: Reticulocyte; HCT: Haematocrit; MCV: Mean corpuscular volume; MCH: Mean corpuscular haemoglobin; MCHC: Mean corpuscular haemoglobin concentration; WBC: White Blood corpuscle

\section{Table 4: Effect of Sub acute toxicity study of Herbal Mixture (HM) on biochemical parameters in mice.}

\begin{tabular}{|c|c|c|c|c|c|c|c|c|}
\hline Parameters & \multicolumn{2}{|c}{ Control } & \multicolumn{2}{c|}{ HM 100mg/kg } & \multicolumn{2}{c|}{ HM 200mg/kg } & \multicolumn{2}{c|}{ HM 400mg/kg } \\
\hline & Male & Female & Male & Female & Male & Female & Male & Female \\
\hline (AST (IU/L) & $101.3 \pm 12.0$ & $105.2 \pm 11.2$ & $106.6 \pm 12.56$ & $104.1 \pm 11.5$ & $100.5 \pm 11.27$ & $100.3 \pm 12.7$ & $102.4 \pm 11.58$ & $101.7 \pm 14.5$ \\
\hline ALT (IU/L) & $19.46 \pm 6.87$ & $21.5 \pm 5.2$ & $20.56 \pm 5.14$ & $19.6 \pm 3.8$ & $20.64 \pm 4.29$ & $20.7 \pm 3.9$ & $21.33 \pm 3.58$ & $20.9 \pm 4.5$ \\
\hline ALP (IU/L) & $140.25 \pm 14.25$ & $138.7 \pm 13.1$ & $138.25 \pm 16.11$ & $139.4 \pm 15.2$ & $142.57 \pm 19.65$ & $142.5 \pm 14.6$ & $145.28 \pm 17.54$ & $144.2 \pm 1.6$ \\
\hline $\begin{array}{c}\text { Blood sugar } \\
\text { (mg/dl) }\end{array}$ & $82.33 \pm 12.5$ & $81.0 \pm 12.6$ & $79.33 \pm 11.29$ & $79.4 \pm 12.9$ & $82.5 \pm 13.64$ & $80.2 \pm 11.4$ & $81.02 \pm 11.05$ & $82.4 \pm 11.5$ \\
\hline BUN (mg/dl) & $19.67 \pm 6.87$ & $18.9 \pm 5.9$ & $19.32 \pm 5.14$ & $19.2 \pm 4.8$ & $18.96 \pm 4.29$ & $18.7 \pm 4.1$ & $18.57 \pm 3.58$ & $19.6 \pm 3.9$ \\
\hline $\begin{array}{c}\text { Creatinine } \\
\text { (mg/dl) }\end{array}$ & $0.785 \pm 0.5$ & $0.765 \pm 0.4$ & $0.766 \pm 0.4$ & $0.745 \pm 0.6$ & $0.766 \pm 0.3$ & $0.714 \pm 0.9$ & $0.754 \pm 0.4$ & $0.754 \pm 0.5$ \\
\hline $\begin{array}{c}\text { Cholesterol } \\
\text { (mg/dl) }\end{array}$ & $122.7 \pm 14.0$ & $121.3 \pm 11.9$ & $118.2 \pm 14.7$ & $122.5 \pm 11.2$ & $115.6 \pm 12.5$ & $119.6 \pm 11.6$ & $116.3 \pm 12.3$ & $115.7 \pm 11.9$ \\
\hline $\begin{array}{c}\text { Triglycerides } \\
\text { mg/dl) }\end{array}$ & $74.5 \pm 9.65$ & $75.8 \pm 8.54$ & $77.5 \pm 8.55$ & $76.1 \pm 7.8$ & $78.5 \pm 5.21$ & $75.6 \pm 7.5$ & $74.5 \pm 8.47$ & $72.1 \pm 6.9$ \\
\hline HDL (mg/dl) & $59.17 \pm 4.21$ & $60.2 \pm 4.2$ & $61.6 \pm 3.22$ & $59.4 \pm 3.2$ & $60.7 \pm 6.01$ & $61.3 \pm 5.1$ & $60.9 \pm 6.05$ & $61.5 \pm 4.2$ \\
\hline LDL I (mg/dl) & $55 \pm 6.54$ & $48.2 \pm 6.5$ & $41.1 \pm 5.97$ & $42.5 \pm 3.6$ & $45.2 \pm 5.49$ & $49.6 \pm 2.8$ & $55.1 \pm 3.64$ & $55.2 \pm 2.6$ \\
\hline VLDL (mg/dl) & $14.43 \pm 2.51$ & $13.2 \pm 2.3$ & $17.32 \pm 2.64$ & $14.2 \pm 2.4$ & $15.8 \pm 1.23$ & $15.1 \pm 1.9$ & $16.2 \pm 2.11$ & $15.1 \pm 1.2$ \\
\hline
\end{tabular}

Values are mean \pm S.D ( $n=6$ per group). Control and treatment groups were compared statistically using one-way ANOVA followed by Dunnett's test.

Table 5: Serum MDA level as studied across the group C (Control); LD (Low dose); MD (Middle dose); HD (High
dose).

Data are expressed as mean \pm standard deviation $(n=6)$. 


\section{CONCLUSION}

The present Acute and sub-acute toxicity results suggest that $\mathrm{LD}_{50}$ of developed formulation $>2000 \mathrm{mg} / \mathrm{kg}$. Further studies on long term toxicity and clinical trials may be rational to substantiate the study results.

\section{ACKNOWLEDGEMENT}

The authors are thankful to University Grant Commission, New Delhi, India for providing financial grants. [F.PSW- 074/05-06(ERO) dated 21.03.2006].

\section{CONFLICT OF INTEREST}

Authors disclose no conflicts of interest for publication of the manuscript.

\section{ABBREVIATIONS}

HM: Herbal Mixture; OECD: The Organisation for Economic Co-operation and Development; $\mathbf{L D}_{50}$ : Lethal Dose 50; WHO: World Health Organization; CPCSEA: Committee for the Purpose of Control and Supervision of Experiments on Animals; AOT: Acute Oral Toxicity; EDTA: Ethylenediaminetetraacetic Acid; TSC: Tri-sodium citrate; DLC: differential leukocyte count; HGB: Haemoglobin; RBC: Red blood cell; WBC: White blood cell; HCT: Haematocrit; ALP: alkaline phosphatase; AST: aspartate transaminase; ALT: Alanine transaminase; LDH: Lactate dehydrogenase; PCV: Packed Cell Volume; MCHC: Mean cell Haemoglobin Concentration; MCV: Mean Red Cell Volume; MCH: Mean Cell Hemoglobin; MPV: Mean platelet volume; HDL: High-density lipoprotein; LDL: Low- density lipoprotein; VLDL: Very-Low-Density Lipoprotein; TGL: Triglycerides.

\section{REFERENCES}

1. Dubey NK, Kumar R, Tripathi P. Global promotion of herbal medicine: India's opportunity. Current Science. 2004;86(1):37-41.

2. Ogbonnia S, Adekunle AA, Bosa MK, Enwuru VN. Evaluation of acute and subacute toxicity of Alstoniacongensis Engler (Apocynaceae) bark and Xylopia aethiopica (Dunal) A. Rich (Annonaceae) fruits mixtures used in the treatment of diabetes. Afr J Biotechnol. 2008;7(6):701-5.

3. Kroll DJ, Shaw HS. Complementary and Alternative Medicine (CAM): Relevance to laboratory medicine. Clin Laboratory Int. 2003;27(3):14-6.

4. Rickert K, Martinez RR, Martinez TT. Pharmacist knowledge of common herbal preparations. Proc West Pharmacol Soc. 1999;42:1-2.

5. Asira T, Shariq S, Roohi Z. Acute toxicity study of a polyherbal Unani formulation Habbe Shifa in experimental animal model. Indian Journal of Traditional Knowledge. 2014;13(1):171-4.

6. Girish C, Koner BC, Jayanthi S, Rao KR, Rajesh B, Pradhan SC. Hepatoprotective activity of six polyherbal formulations in paracetamol induced liver toxicity in mice. Indian J Med Res. 2009;129(5):569-78.

7. Riaz A, Khan RA, Ahmed S, Afroz S. Assessment of acute toxicity and reproductive capability of a herbal combination. Pak J Pharm Sci. 2010;23(3):291-4.

8. Joshi CS, Priya ES, Venkataraman S. Acute and subacute toxicity studies on the polyherbal antidiabetic formulation Diakyur in experimental animal models. Journal of Health Science. 2007;53(2):245-9.

9. Lahlou S, Israili ZH, Lyoussi B. Acute and chronic toxicity of a lyophilised aqueous extract of Tanacetumvulgare leaves in rodents. J Ethnopharmacol. 2008;117(2):221-7.

10. Saad B, Azaizeh H, AbuHijleh G, Said O. Safety of traditional arab herbal medicine. Evid Based Complement Alternat Med. 2006;3(4):4339.

11. Humber JM. The role of complementary and alternative medicine: Accomodating pluralism. J Am Med Assoc. 2002;288:1655-6.

12. Joshi CS, Priya ES, Venkataraman S. Acute and subacute toxicity studies on the polyherbal antidiabetic ormulationdiakyur in experimental animal models. J Health Sci. 2007;53(2):245-9.

13. Park M, Choi H, Kim J, Lee H, Ku S. 28 days repeated oral dose toxicity test of aqueous extracts of Mahwangyounpae-tang, a polyherbal formula. Food Chem Toxicol. 2010;48(8-9):2477-82.

14. Cheng CW, Bian ZX, Wu TX. Systematic review of Chinese herbal medicine for functional constipation. World J Gastroenterol. 2009;15(39):4886-95.

\section{SUMMARY}

- Herbal medicines are the most popular form of therapy for most of the world's population. A large number of populations in the developing countries still rely on herbal medicine practitioners to meet their primary healthcare needs. Toxicology constitutes an essential role in the development of herbal medicines. With the advancements of analytical techniques and molecular technology, coupling with the conventional test systems, the '-omic-' technology makes a significant contribution to the predictive and preclinical toxicology of herbal medicine.

- The purpose of this study was to evaluate and assess the potential acute and subacute toxicity (28-day) of Herbal Mixture (HM) administered orally to mice by single and repeated dosing, respectively; and to provide information to assist in selection of doses for future repeated-dose studies.

- Based on our results, we conclude that HM were found to be safe up to a dose of $2000 \mathrm{mg} / \mathrm{kg}$. Hematological, biochemical and histopathological investigations clearly demonstrates that single oral administration upto $2000 \mathrm{mg} / \mathrm{kg}$ in acute toxicity study and daily oral administration of the HM for 28 days upto $400 \mathrm{mg} / \mathrm{kg}$ in sub-acute toxicity study caused no significant adverse changes in the organs like heart, lungs, liver, spleen and kidney. 


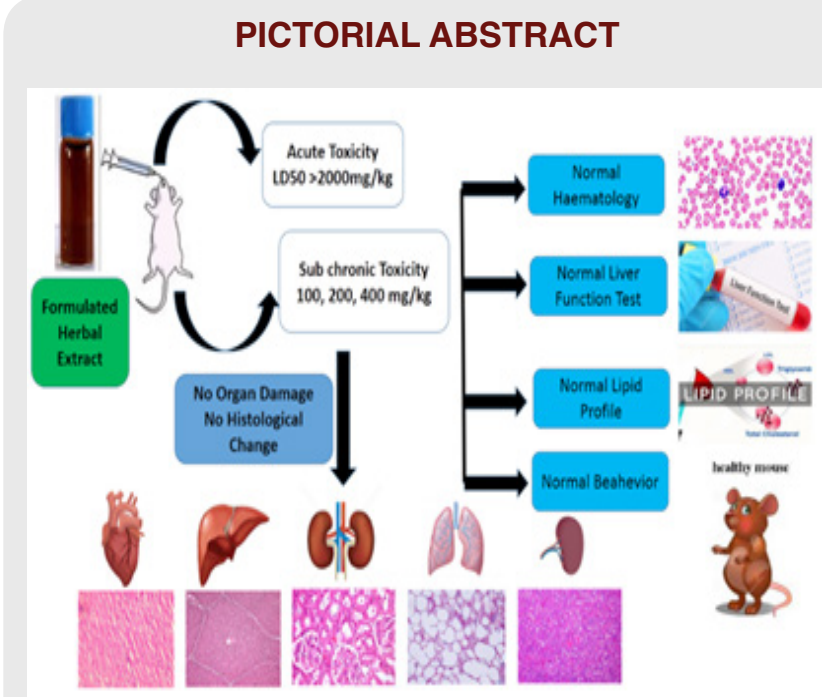

About Authors

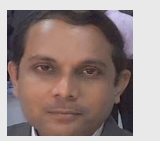

Soumendra Darbar, Research Scientist, Faculty Council of Science, Jadavpur University, 188, Raja SC Mullick Road, Kolkata 700 032, West Bengal, India.

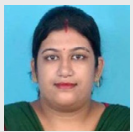

Srimoyee Saha, Research Scholar, Department of Physics, Jadavpur University, Kolkata 700 032, West Bengal, India.

Kausikisankar Pramanik, Professor, Department of Chemistry, Jadavpur University, 188, Raja SC Mullick Road, Kolkata 700 032, West Bengal, India.

Atiskumar Chattopadhyay, Principal Secretary, Faculty Council of Science, Jadavpur University, 188, Raja SC Mullick Road, Kolkata 700 032, West Bengal, India.

Cite this article: Darbar S, Saha S, Pramanik K, Chattopadhyay A. Preliminary Assessment of Acute and 28Day Repeated Dose Oral Toxicity of a Newly Developed Herbal Mixture on Experimental Animal. Indian $\mathrm{J}$ of Pharmaceutical Education and Research. 2020;54(1):135-42. 